\title{
Metal-Organic Framework MIL-53(Fe): Synthesis, Electrochemical Characterization, and Application in Development of a Novel and Sensitive Electrochemical Sensor for Detection of Cadmium Ions in Aqueous Solutions
}

\author{
Hoang Vinh Tran $(\mathbb{D}$, Hue Thi Minh Dang $\mathbb{D}$, Luyen Thi Tran $\mathbb{D}$, Chau Van Tran, \\ and Chinh Dang Huynh
}

School of Chemical Engineering, Hanoi University of Science and Technology, 1 Dai Co Viet Road, Hanoi 100000, Vietnam

Correspondence should be addressed to Hue Thi Minh Dang; hue.dangthiminh@hust.edu.vn

and Luyen Thi Tran; luyen.tranthi@hust.edu.vn

Received 23 July 2020; Revised 7 September 2020; Accepted 15 September 2020; Published 6 October 2020

Academic Editor: Sagar Roy

Copyright (C) 2020 Hoang Vinh Tran et al. This is an open access article distributed under the Creative Commons Attribution License, which permits unrestricted use, distribution, and reproduction in any medium, provided the original work is properly cited.

\begin{abstract}
A metal-organic framework MIL-53(Fe) was successfully synthesized by a simple hydrothermal method. A synthesized MIL-53(Fe) sample was characterized, and results indicated that the formed MIL-53(Fe) was a single phase with small particle size of $0.8 \mu \mathrm{m}$ and homogeneous particle size distribution was obtained. The synthesized MIL-53(Fe) has been used to modify a glassy carbon electrode (GCE) by a drop-casting technique. Cyclic voltammetry (CV) and electrochemical impedance spectroscopy (EIS) measurements of the MIL-53(Fe)-modified GCE showed that the MIL-53(Fe) was successfully immobilized onto the GCE electrode surface and the electrochemical behavior of the GCE/MIL-53(Fe) electrode was stable. In addition, several electrochemical parameters of MIL-53(Fe)-modified GCE (GCE/MIL-53(Fe)) including the heterogeneous standard rate constant $\left(k^{0}\right)$ and the electrochemically effective surface area $(A)$ were calculated. Obtained results demonstrated that the synthesized MIL-53(Fe) with the small particle size, highly homogeneous particle size, and high electrochemically effective surface area was able to significantly enhance the electrochemical response signal of the working electrode. Therefore, the GCE/MIL-53(Fe) electrode has been used as a highly sensitive electrochemical sensor for cadmium ion (Cd(II)) monitoring in aqueous solution using differential pulse voltammetry (DPV) technique. The response signal of the electrochemical sensor increased linearly in the $\mathrm{Cd}(\mathrm{II})$ ion concentration range from $150 \mathrm{nM}$ to $450 \mathrm{nM}$ with the limit of detection (LOD) of $16 \mathrm{nM}$.
\end{abstract}

\section{Introduction}

The pollution of water sources caused by heavy metal ions, inorganic substances, organic matters, and bacteria from different agricultural, industrial, and medical waste sources has seriously affected people's lives and the ecosystems and organisms in the aquatic environment [1-3]. Determining the concentration of pollutants is an important step in environmental monitoring and supervision and is a basis for offering solutions to protect the environment. Chromatography and its associated techniques such as atomic emission spectroscopy (AES), atomic fluorescence spectroscopy
(AFS), atomic absorption spectroscopy, and inductively coupled plasma mass spectrometry are common and effective methods for identifying environmental contaminants $[3,4]$. However, the above techniques showed many disadvantages such as long testing times, expensive equipment, and complex measurement processes $[3,5]$. Therefore, development of new techniques, which possess the advantages of high sensitivity, quick detection, and ease of use, is needed for the onsite, real-time, and continuous monitoring of environmental pollutants [6-11].

In which, electrochemical sensors can offer advantages of low detection limits, wide linear response ranges, and good 
stability and reproducibility. Moreover, electrochemical sensors can be easily prepared from many advanced materials to improve sensitivity and selectivity. In general, an electrochemical sensor is configured from two main parts, which are named a sensing element and a transducer. When the sensing element interacts with an analyte, the transducer can convert the sensed information into an electrical signal $[10,12-14]$. The important characteristics of the sensor include sensitivity, stability, selectivity, response time, cost, and reusability [9]. To improve the sensitivity of electrochemical sensors, advanced materials have been applied to modified electrodes, including nanostructured conducting polymers [12, 15], metal and metal oxide nanoparticles [16-18], nanostructured carbon materials (such as porous carbon, carbon nanotube, and graphene/graphene oxide) [17-19], and metal-organic frameworks (MOFs) [6, 9, 2024]. Among them, MOF materials which are constructed by metal ions or clusters and organic ligands via coordination bonds have unique properties including their structural diversity, flexible framework functionality, large metal cluster density, high stability, abundant adsorption sites, and a large surface area exceeding that of activated carbons and zeolites which are traditional porous materials [9, 21, 23-26]. Moreover, the physical and chemical characteristics of MOFs can be customized and precisely designed, depending on how they are synthesized [27]. The development of MOF material-based electrochemical sensors for determining pollutants in water has practical significance and high potential in the field of the environment $[9,28]$. Therefore, a number of MOFs have been used in electrochemical sensors to detect organic substances, inorganic ions, antibiotics, and heavy metals in aqueous solutions [9, 20-24, 26, 29, 30].

MIL-53(Fe) (MIL: Materials of Institute Lavoisier), a class of MOFs generated by a combination between iron(III) cations and 1,4-dicarboxylic acid, consists of threedimensional networks or secondary building units which contain $\mathrm{FeO}_{6}$ hexagonal chains and dicarboxylate anions [31]. The emergent features of MIL-53(Fe) compared with other MOFs are chemically stable and have lower toxic metal centers and green, sustainable pathways for fabrication [31]. However, only few works have been dedicated to the development of an electrochemical sensor based on MIL-53 for detection of heavy metal ions in aqueous solutions (MIL53(Al) [10]). Therefore, in this work, an effective hydrothermal method was carried out to synthesize a metal-organic framework MIL-53(Fe), which was then used to modify the glassy carbon electrode (GCE) for sensitive electrochemical determination of $\mathrm{Cd}(\mathrm{II})$ ion concentration in aqueous solutions. In addition, the specific characteristics of the synthesized MIL-53(Fe) were also carefully analyzed by various chemical-physical techniques.

\section{Experimental}

\subsection{Chemicals and Instrumentations}

2.1.1. Chemicals. Iron(III) chloride hexahydrate $\mathrm{FeCl}_{3} \cdot 6 \mathrm{H}_{2} \mathrm{O}$ (99\%wt.), terephthalic acid $\mathrm{C}_{6} \mathrm{H}_{4}-1,4-(\mathrm{COOH})_{2}$ (TPA) (98\%wt.), methanol $\mathrm{CH}_{3} \mathrm{OH}(\mathrm{MeOH})$ (anhydrous, 99.8\% v/ v), sodium acetate $\mathrm{CH}_{3} \mathrm{COONa}$ (99\%wt.), and cadmium nitrate tetrahydrate $\mathrm{Cd}\left(\mathrm{NO}_{3}\right)_{2} \cdot 4 \mathrm{H}_{2} \mathrm{O}$ (99\%wt.) were purchased from Sigma-Aldrich. Dimethylformamide $\mathrm{C}_{3} \mathrm{H}_{7} \mathrm{NO}$ (DMF) (99.94\%) was purchased from Fisher Chemical. Polyethylene glycol $2000\left(\mathrm{H}\left(\mathrm{OCH}_{2} \mathrm{CH}_{2}\right)_{n} \mathrm{OH}, \mathrm{PEG} 2000\right)$ was purchased from Alfa Aesar. Chitosan (CS, MW =400,000 $\mathrm{g} \mathrm{mol}^{-1}$, degree of acetylation $(\mathrm{DA})=70 \%$ ) was prepared by deacetylation of chitin in our laboratory [32, 33]. Acetate buffer solution $0.1 \mathrm{M}$ (ABS) with $\mathrm{pH} 5.0$ was prepared by using the appropriate amounts of sodium acetate and acetic acid.

2.1.2. Instrumentations. A PGSTAT302N AutoLab electrochemical workstation (Netherlands) was used to perform electrochemical measurements. X-ray diffraction (XRD) measurements were carried out using a Bruker D8 Advance diffractometer equipped with $\mathrm{Cu}-\mathrm{K} \alpha$ radiation $(\lambda=1.54056$ $\AA$ ). Scanning electron microscope (SEM) images of MIL$53(\mathrm{Fe})$ were investigated using a Hitachi S4800 scanning electron microscope. The structure of MIL-53(Fe) was examined using Fourier transform infrared spectroscopy (FT-IR) spectra measured with a Nicolet 6700 FT-IR spectrometer. Transmission electron microscope (TEM) images were taken using a TECNAI F20-G2 high-resolution transmission electron microscope.

2.2. Synthesis of $M I L-53(\mathrm{Fe}) .0 .623 \mathrm{~g}$ of $\mathrm{FeCl}_{3} \cdot 6 \mathrm{H}_{2} \mathrm{O}$ and $0.383 \mathrm{~g}$ of TPA were mixed in $50 \mathrm{~mL}$ of DMF solvent using an IKA magnetic stirrer with a stirring rate of $200 \mathrm{rpm}$ for 10 minutes to get a solution. Then, the solution was added in an autoclave, and the hydrothermal synthesis was performed at $150^{\circ} \mathrm{C}$ for 12 hours. The product obtained after the hydrothermal process was filtrated, washed with $150 \mathrm{~mL}$ of $\mathrm{MeOH}$ and distilled water, and then dispersed in distilled water and stirred on the IKA magnetic stirrer with a stirring rate of $200 \mathrm{rpm}$ for 15 hours. After that, the product was vacuum-dried at $170^{\circ} \mathrm{C}$ for 12 hours. Finally, the synthesized product was finely ground and stored in a desiccator.

\subsection{Electrochemical Characterizations of $M I L-53(\mathrm{Fe})$ and Detection of Cd(II) Ions Using MOF-Based Electrochemical Sensors}

2.3.1. Fabrication of $\mathrm{MIL}-53(\mathrm{Fe})$-Modified Electrodes. GCE was polished using 0.3 and $0.05 \mu \mathrm{m}$ alumina slurries on a polishing cloth; then, it was cleaned carefully by deionized water and dried under an infrared lamp. A slurry of MIL-53(Fe) was prepared by dispersing $6.0 \mathrm{mg}$ of $\mathrm{MIL}-53(\mathrm{Fe})$ into a $2 \mathrm{~mL}$ mixture of CS solution $\left(10 \mathrm{mg} \mathrm{mL}^{-1}\right.$ in acetic acid $3 \%$ $v / v)$ and $1.0 \mathrm{mg}$ of PEG-2000 using ultrasonic processing for 5 minutes. Finally, $6 \mu \mathrm{L}$ of the MOFs/CS/PEG mixture was drop-casted onto the surface of GCE, and it was dried in the air under an infrared lamp. The MIL-53(Fe)-modified GCE (GCE/MIL-53(Fe)) was obtained.

2.3.2. Electrochemical Measurements. A three-electrode configuration consisted of the GCE/MIL-53(Fe) as a working electrode (WE), a Pt electrode as a counter electrode (CE), and a $\mathrm{Ag} / \mathrm{AgCl}$ electrode as a reference electrode (RE). CV and EIS measurements of the GCE/bare and GCE/MIL- 


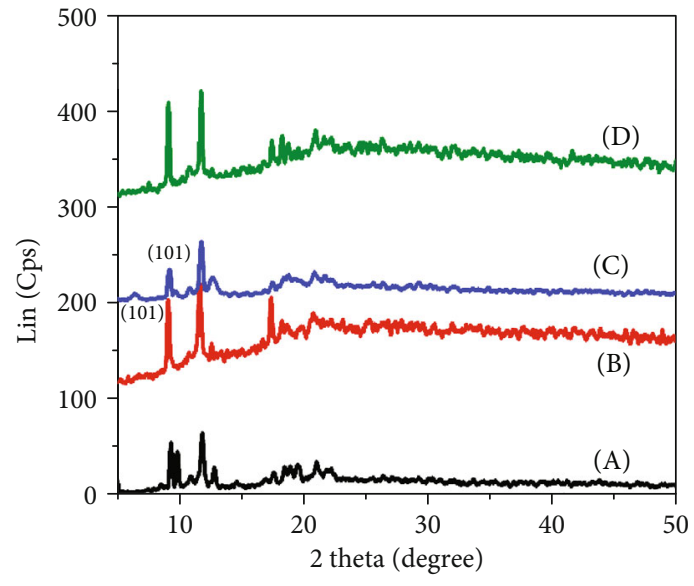

(a)

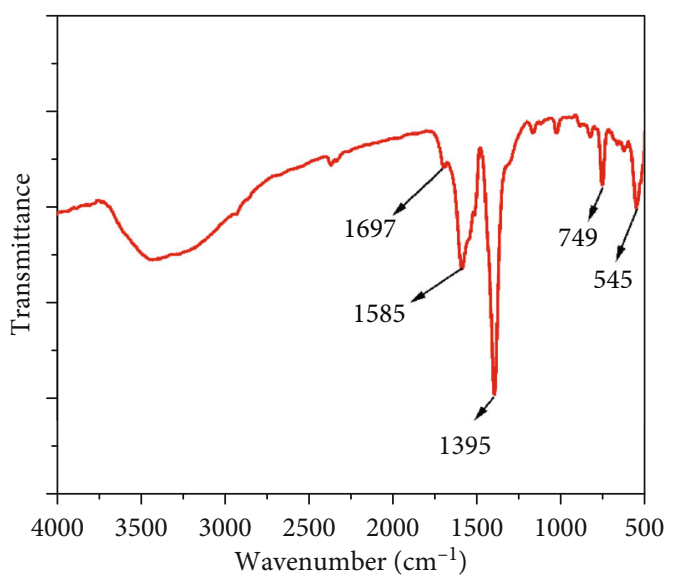

(b)

Figure 1: (a) XRD patterns of the fabricated MIL-53(Fe) samples when the hydrothermal time was (A) $8 \mathrm{~h}$, (B) $12 \mathrm{~h}$, (C) $15 \mathrm{~h}$, and (D) 24 hours; (b) FT-IR spectrum of the fabricated MIL-53(Fe).

$53(\mathrm{Fe})$ electrodes were performed in $\mathrm{K}_{3} \mathrm{Fe}(\mathrm{CN})_{6} / \mathrm{K}_{4} \mathrm{Fe}(\mathrm{CN})_{6}$ $(0.005 \mathrm{M})$ and $0.1 \mathrm{M} \mathrm{KCl}$ solution. CVs were recorded at different scan rates of $25,30,35,40,45,50,55,60,65,70$, and $75 \mathrm{mV} \mathrm{s}^{-1}$. EIS spectra were measured with frequency range: $100 \mathrm{kHz}$ to $100 \mathrm{mHz}, E_{\mathrm{AC}}=5 \mathrm{mV}, E_{\mathrm{DC}}=180 \mathrm{mV}$. Cadmium ions in aqueous solutions were detected using the MOFbased electrochemical sensors with DPV measurements. The electrolyte solutions contained cadmium ions (in ABS) with the concentrations of $150,200,250,300,350,400$, and $450 \mathrm{nM}$. A deposition potential of $-1.2 \mathrm{~V}$ was applied for $120 \mathrm{~s}$ under stirring. After preconcentration, DPV measurements were recorded from -1.1 to $-0.3 \mathrm{~V}$ with a pulse amplitude of $50 \mathrm{mV}$ and width of $50 \mathrm{~ms}$. Before the next detection, the desorption process was performed under the potential of $0.4 \mathrm{~V}$ for $100 \mathrm{~s}$ to remove the residual metal ions.

\section{Results and Discussion}

3.1. Characterizations of MIL-53(Fe). The XRD patterns of as-prepared MIL-53(Fe) samples with various hydrothermal times including $8,12,15$, and 24 hours are presented in Figure 1(a). It can be seen that the samples prepared with the hydrothermal time of 8 hours (Figure 1(a), curve A) and 24 hours (Figure 1(a), curve D) have specific peaks of the MIL-53(Fe); however, there are several peaks belonging to other crystals $[31,34]$. Meanwhile, the XRD patterns of samples prepared with the hydrothermal time of 12 or 15 hours (Figure 1(a), curves B and C, respectively) show only characteristic peaks of MIL-53(Fe) at 9.5, 12.5, and 18.2 degrees of 2-theta [31,34]. These peaks shift slightly compared to the previous reports due to the different reaction conditions $[35,36]$. Comparing XRD patterns of sample B and sample $C$ (samples were synthesized with the hydrothermal time of 12 and 15 hours, respectively), the hydrothermal time for the formation of MIL-53(Fe) was finally chosen to be 12 hours because of the sharper and higher characteristic peaks, which implied that the crystals were formed completely. The FT-IR spectrum of the MIL-53(Fe) (Figure 1(b)) exhibits the typical vibrational bands of the car- boxylic acid function in the region of $1400-1700 \mathrm{~cm}^{-1}$. The adsorption band of the carboxyl group of the ligand coordinated to the $\mathrm{Fe}(\mathrm{III})$ ion is visible at $1585 \mathrm{~cm}^{-1}$. The peak at $749 \mathrm{~cm}^{-1}$ corresponds to the $\mathrm{C}-\mathrm{H}$ bonding vibration of the benzene rings $[37,38]$. Moreover, the presence of the $\mathrm{Fe}-\mathrm{O}$ vibration at $545 \mathrm{~cm}^{-1}$ indicates the formation of a metaloxo bond between the carboxylic group of terephthalic acid and the Fe(III) [39].

The surface morphology of the MIL-53(Fe) was investigated by using SEM that is shown in Figure 2(a), which can be observed that the MIL-53(Fe)'s particle size is quite small and homogeneous with the distribution of the particle size around $0.8 \mu \mathrm{m}$ (Figure 2(b)). The TEM images (Figures 2(c) and $2(\mathrm{~d})$ ) indicate that there are small pseudospherical particles in the range of $5-8 \mathrm{~nm}$ which were attached to the surface of the MIL-53(Fe) crystals [26]. The small particle size and the homogeneous particle size distribution of the obtained MIL-53(Fe) have an important role in improving the repeatability and reproducibility of electrochemical sensors.

3.2. Electrochemical Characterizations of MIL-53( $\mathrm{Fe})$. Figure 3 shows the CV (Figure 3(a)) and EIS spectra (Figure 3(b)) of the GCE/bare (curve A) and GCE/MIL$53(\mathrm{Fe})$ (curve B) electrodes performed in $\mathrm{K}_{3} \mathrm{Fe}(\mathrm{CN})_{6} / \mathrm{K}_{4}$ $\mathrm{Fe}(\mathrm{CN})_{6}(0.005 \mathrm{M})$ and $0.1 \mathrm{M} \mathrm{KCl}$ solution. It can be seen that there are two peaks on the two CV curves corresponding to the oxidation of $\mathrm{Fe}(\mathrm{CN})_{6}{ }^{4-}$ and the reduction of $\mathrm{Fe}(\mathrm{CN})_{6}^{3}$ - (Figure 3(a)). In the case of the GCE/MIL-53(Fe) electrode (curve $\mathrm{B}$ ), the peak current is higher than that of the bare GCE electrode (curve A). This result can be attributed to the increase in the electroactive area when the MIL-53(Fe) was loaded on the GCE, leading to the accumulation of the electroactive species on the electrode surface and the increase in the current density. The EIS spectra (Figure 3(b)) of the two different electrodes consist of two parts: a semicircle which characterizes the charge transfer process and a linear region which characterizes the diffusion process. These EIS spectra can be simulated by an equivalent circuit based on the Randles model (Figure 3(b), inset). This equivalent circuit 


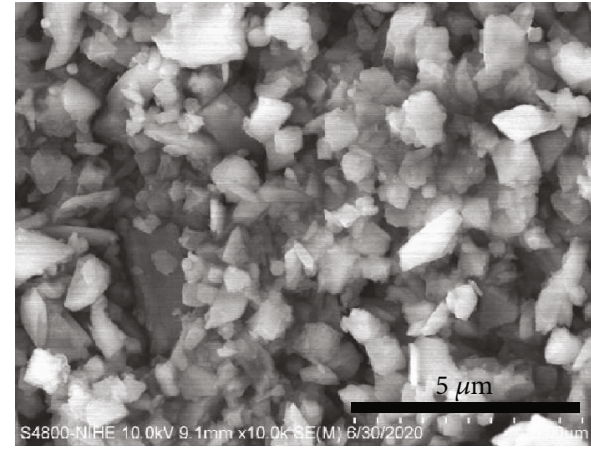

(a)

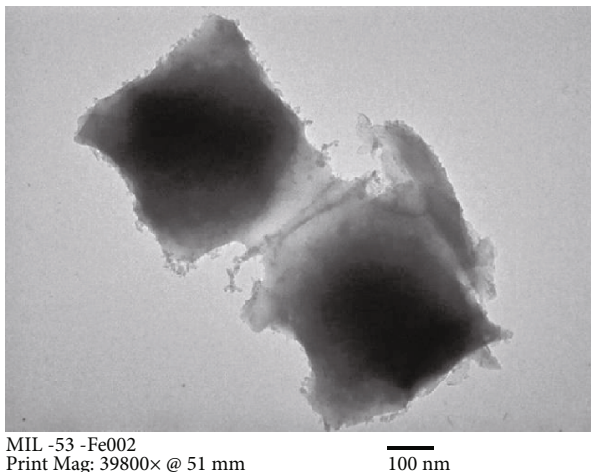

(c)

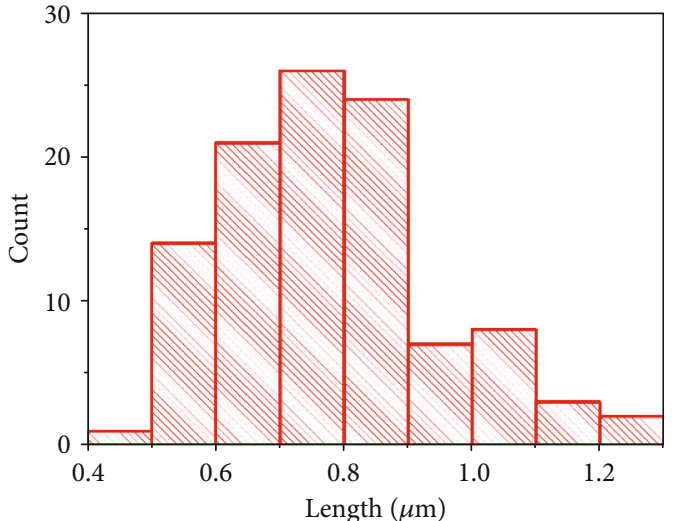

(b)

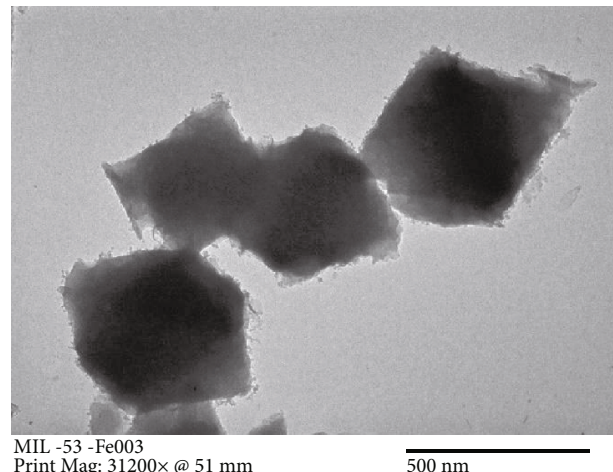

(d)

Figure 2: (a) SEM image; (b) particle diameter distribution; (c, d) TEM images of the synthesized MIL-53(Fe).

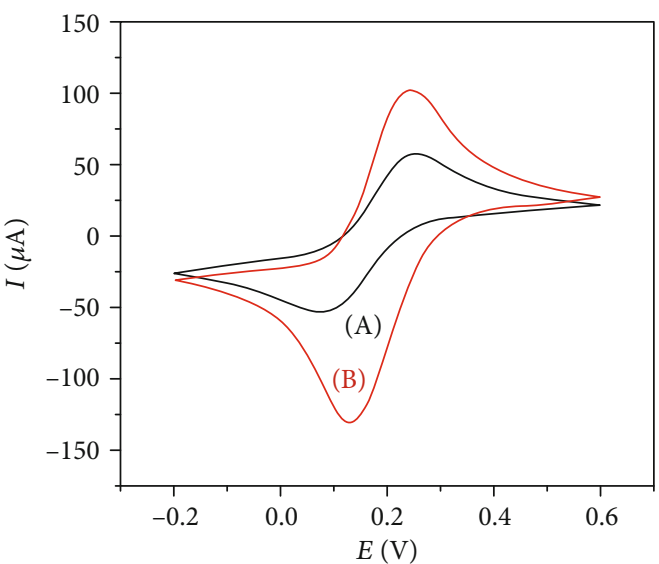

(a)

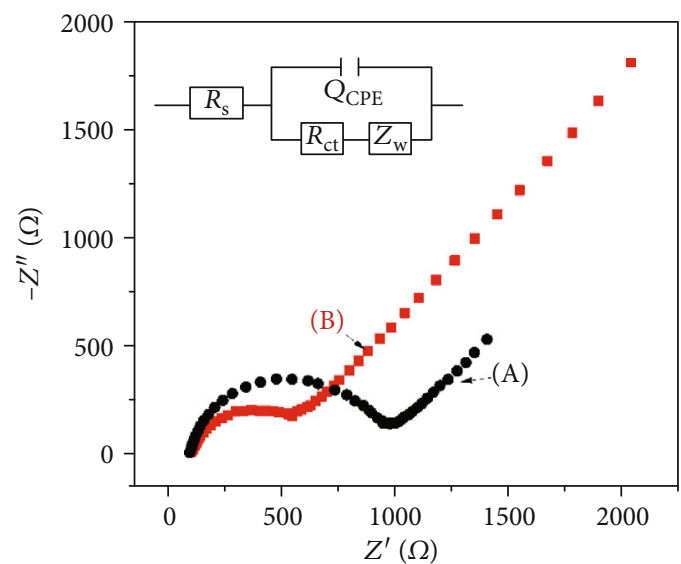

(b)

Figure 3: (a) Cyclic voltammograms of (A) GCE/bare and (B) GCE/MIL-53(Fe) electrodes; (b) EIS spectra (Nyquist plots) of (A) GCE/bare and (B) GCE/MIL-53(Fe) electrodes (inset: Randles equivalent circuit). Experimental conditions: $\mathrm{K}_{3} \mathrm{Fe}(\mathrm{CN})_{6} / \mathrm{K}_{4} \mathrm{Fe}(\mathrm{CN})_{6}(0.005 \mathrm{M})$ and $0.1 \mathrm{M}$ $\mathrm{KCl}$ solution. CVs were recorded at a scan rate of $30 \mathrm{mV} \mathrm{s}^{-1}$. EIS spectra were measured with frequency range $100 \mathrm{kHz}$ to $100 \mathrm{mHz}$, $E_{\mathrm{AC}}=5 \mathrm{mV}, E_{\mathrm{DC}}=180 \mathrm{mV}$.

consists of a solution resistance $\left(R_{\mathrm{s}}\right)$, a charge transfer resistance $\left(R_{\mathrm{ct}}\right)$, a constant phase element $\left(Q_{\mathrm{CPE}}\right)$, and a Warburg diffusion coefficient $(W)$. Fitted $R_{\mathrm{ct}}$ results of the GCE/MIL$53(\mathrm{Fe})$ and bare GCE were $425 \Omega$ and $828 \Omega$, respectively, which implied that the MIL-53(Fe) layer-modified GCE with the small particle size, the homogeneous particle size distri- bution, and the high electrochemically effective surface area was able to significantly enhance the electrochemical response of the working electrode. These EIS results are suitable for the CV results obtained in Figure 3(a).

CVs of the GCE/MIL-53(Fe) electrode in $0.1 \mathrm{M} \mathrm{KCl}$ solution containing $5 \mathrm{mM} \mathrm{Fe}(\mathrm{CN})_{6}^{3-/ 4-}$ at different scan rates 

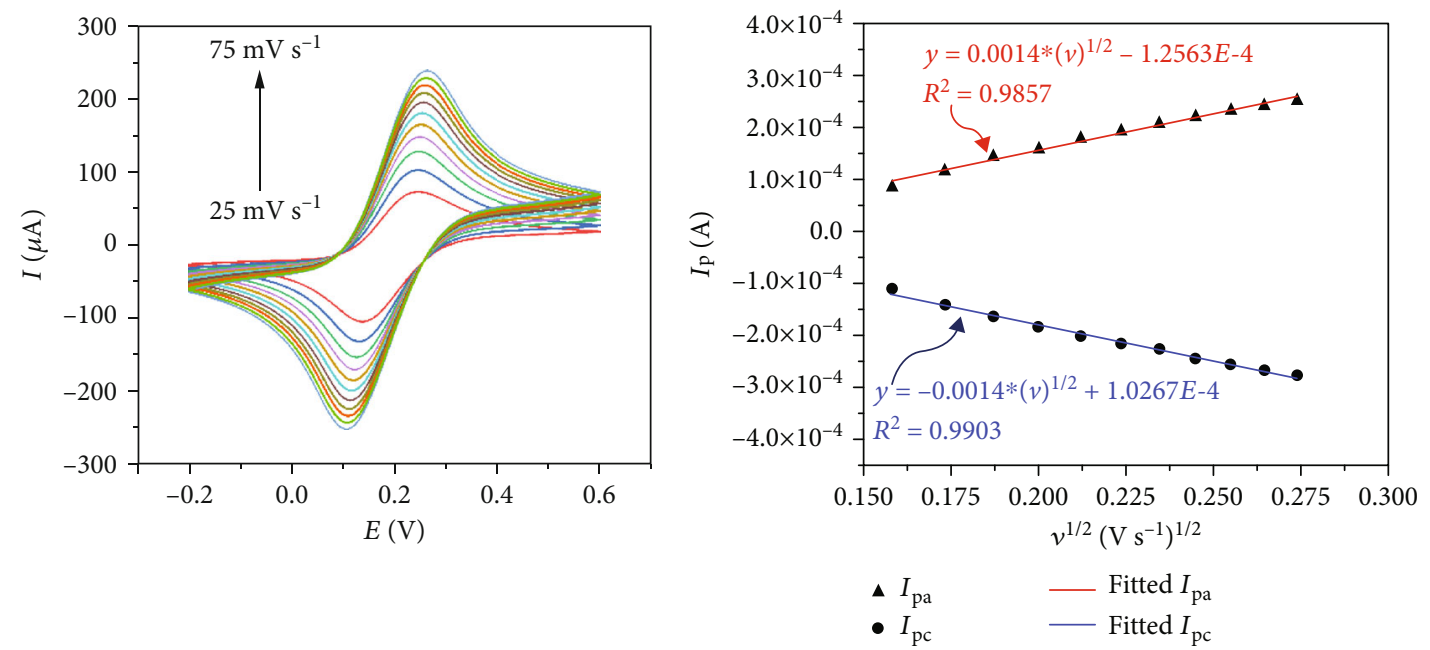

(a)

(b)

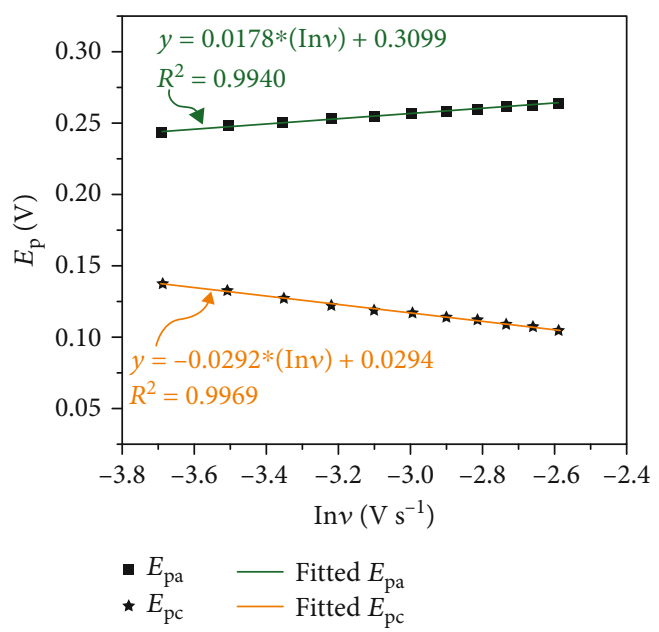

(c)

Figure 4: (a) Cyclic voltammograms of the GCE/MIL-53(Fe) electrode in $0.1 \mathrm{M} \mathrm{KCl}$ solution containing $5 \mathrm{mM} \mathrm{Fe}(\mathrm{CN})_{6}{ }^{3-/ 4-}$ at different scan rates of $25,30,35,40,45,50,55,60,65,70$, and $75 \mathrm{mV} \mathrm{s}^{-1}$; (b) the relationships between the currents of anodic and cathodic peaks and the square root of the scan rate $\left(v^{1 / 2}\right)$ and their corresponding linear fit lines: $I_{\mathrm{pa}}$, the red line with the triangle symbols, and $I_{\mathrm{pc}}$, the blue line with the circle symbols; (c) the relationships between the potentials of anodic and cathodic peaks and $\ln v$ and their corresponding linear fit lines: $E_{\mathrm{pa}}$, the green line with the square symbols, and $E_{\mathrm{pc}}$, the orange line with the star symbols.

from 25 to $75 \mathrm{mV} \mathrm{s}^{-1}$ are shown in Figure 4(a). From these obtained data, the relationships between the currents of anodic and cathodic peaks and the square root of the potential scan rate are plotted in Figure 4(b), i.e., with the relationship between $I_{\mathrm{pa}}$ vs. $v^{1 / 2}$ (marked by the red line with the triangle symbols)

$$
y=0.0014 \times v^{1 / 2}-1.2563 \times 10^{-4}\left(R^{2}=0.9857\right)
$$

and $I_{\mathrm{pc}}$ vs. $v^{1 / 2}$ (the blue line with the circle symbols)

$$
y=-0.0014 \times v^{1 / 2}+1.0267 \times 10^{-4}\left(R^{2}=0.9903\right) .
$$

In the cases of both anodic and cathodic peaks, the peak currents expressed linear dependence on the square root of the potential scan rate, indicating that the electrochemical processes occurred in a diffusion-controlled regime on the MIL-53(Fe)-modified GCE electrode [40]. Besides, the relationships between the potentials of anodic and cathodic peaks and $\ln v$ were investigated, and their corresponding linear fit lines for each set of experimental data have been shown in Figure $4(\mathrm{c})$, i.e., $E_{\mathrm{pa}}$ vs. $\ln v$ (the green line with the square symbols)

$$
y=0.0178 \times \ln v+0.3099\left(R^{2}=0.9940\right)
$$

and $E_{\mathrm{pc}}$ vs. $\ln v$ (the orange line with the star symbols)

$$
y=-0.0292 \times \ln v+0.0294\left(R^{2}=0.9969\right) .
$$

The gradually increasing trend of the potential peak difference $\left(\Delta E=E_{\mathrm{pa}}-E_{\mathrm{pc}}\right)$ with the potential scan rate $v$ 


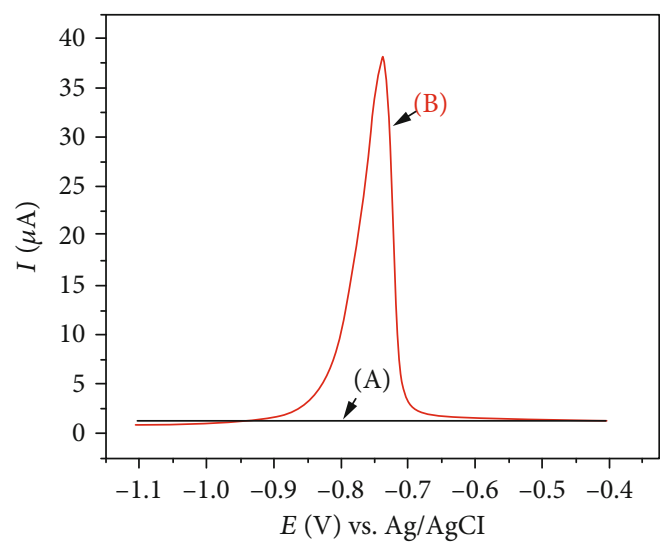

Figure 5: DPV results of (a) GCE/bare and (b) GCE/MIL-53(Fe) electrodes measured in $20 \mu \mathrm{M} \mathrm{Cd}(\mathrm{II})$ and $0.1 \mathrm{M} \mathrm{ABS}(\mathrm{pH}=5.0)$ solution.

demonstrates that the electrochemical processes which happened on the GCE/MIL-53(Fe) electrode surface are quasireversible [41]. Moreover, as can be seen in Figure 4(c), both the potentials of anodic and cathodic peaks depend linearly on the natural logarithm of the scan rate, and these relationships can be expressed by the following equations [41, 42]:

$$
E_{\mathrm{pa}}=E^{0}+m\left[0.78+\ln \left(\frac{D^{1 / 2}}{k^{0}}\right)-0.5 \ln m\right]+0.5 m \ln v,
$$

$$
\begin{gathered}
m=\frac{R T}{(1-\alpha) n F}, \\
E_{\mathrm{pc}}=E^{0}-m^{\prime}\left[0.78+\ln \left(\frac{D^{1 / 2}}{k^{0}}\right)-0.5 \ln m^{\prime}\right]-0.5 m^{\prime} \ln v
\end{gathered}
$$

$$
m^{\prime}=\frac{R T}{\alpha n F},
$$

where $v\left(\mathrm{~V} \mathrm{~s}^{-1}\right)$ is the scan rate, $E^{0}(\mathrm{~V})$ is the formal standard potential, $\alpha$ is the charge transfer coefficient, $n$ is the number of transported electrons, $k^{0}\left(\mathrm{~cm} \mathrm{~s}^{-1}\right)$ is the electron transfer rate constant, $D\left(\mathrm{~cm}^{2} \mathrm{~s}^{-1}\right)$ is the diffusion coefficient, $R$ is gas constant $\left(R=8.314 \mathrm{~J} \mathrm{~mol}^{-1} \mathrm{~K}^{-1}\right), T$ is working temperature $(T=298 \mathrm{~K})$, and $F$ is Faraday's constant $(F=96480$ $\left.\mathrm{C} \mathrm{mol}^{-1}\right)$. The values of $\alpha$ and $n$ can be calculated from the slopes of $E_{\mathrm{pa}}$ vs. $\ln v$ and $E_{\mathrm{pc}}$ vs. $\ln v$, and the results are that the value of $\alpha$ is 0.379 and the value of $n$ is 1.161 . The value of $n$ verified that the oxidation of $\mathrm{Fe}(\mathrm{CN})_{6}{ }^{4-}$ and the reduction of $\mathrm{Fe}(\mathrm{CN})_{6}{ }^{3-}$ which occurred on the GCE/MIL-53(Fe) electrode surface are through monoelectronic steps. The diffusion coefficients $\left(D_{O}\right.$ and $\left.D_{R}\right)$ of ferri- and ferrocyanide ions in $0.1 \mathrm{M} \mathrm{KCl}$ medium at $25^{\circ} \mathrm{C}$ are $7.20 \times 10^{-6} \mathrm{~cm}^{2} \mathrm{~s}^{-1}$ and $6.66 \times 10^{-6} \mathrm{~cm}^{2} \mathrm{~s}^{-1}$, respectively [43]. From the intercepts of $E_{\mathrm{pa}}$ vs. $\ln v$ and $E_{\mathrm{pc}}$ vs. $\ln v$ and using $E^{0}=\left(E_{\mathrm{pa}}+\right.$ $\left.E_{\mathrm{pc}}\right) / 2=0.19 \mathrm{~V}$ [41], the values of $k^{0}$ were calculated as
$1.069 \times 10^{-3} \mathrm{~cm} \mathrm{~s}^{-1}$ and $1.489 \times 10^{-3} \mathrm{~cm} \mathrm{~s}^{-1}$ for the anodic and the cathodic branches, respectively, and the average value was $1.279 \times 10^{-3} \mathrm{~cm} \mathrm{~s}^{-1}$. These results further confirmed that, in the considered scan rate range, the oxidation of $\mathrm{Fe}(\mathrm{CN})_{6}{ }^{4-}$ and the reduction of $\mathrm{Fe}(\mathrm{CN})_{6}{ }^{3-}$ which occurred on the GCE/MIL-53(Fe) electrode surface are quasireversible.

The electrochemically effective surface area $(A)$ of modified electrodes is an important factor increasing electrochemical active sites, enhancing electrochemical response, and improving sensitivity of electrochemical sensors [44]. In this work, the electrochemically effective surface area of the GCE/MIL-53(Fe) electrode was determined by CV data analysis by using the Randles-Sevcik equation for quasireversible reactions as follows [45]:

$$
I_{p}=3.01 \times 10^{5} \alpha^{1 / 2} n^{3 / 2} A C_{0} D^{1 / 2} v^{1 / 2},
$$

where $v\left(\mathrm{~V} \mathrm{~s}^{-1}\right), \alpha, n$, and $D\left(\mathrm{~cm}^{2} \mathrm{~s}^{-1}\right)$ were mentioned in Equations (5)-(8). $A\left(\mathrm{~cm}^{2}\right)$ is the electrochemically effective surface area of the electrode, $C_{0}\left(\mathrm{~mol} \mathrm{~cm}^{-3}\right)$ is the concentration of redox species, and $I_{\mathrm{p}}(\mathrm{A})$ is the redox peak current. From Equation (9) and using the slope of the linear dependence of the anodic peak current on the square root of the potential scan rate (Figure 4(b)), the value of $A$ of the GCE/MIL-53(Fe) electrode was calculated to be $0.453 \mathrm{~cm}^{2}$. Thus, the electrochemically effective surface area of the modified GCE electrodes using the synthesized MIL-53(Fe) is significantly larger than that of the GCE electrodes $\left(A_{\mathrm{GCE}}=0.071\right.$ $\mathrm{cm}^{2}$ ). The above EIS and CV results verified that the synthesized MIL-53(Fe) material was successfully immobilized on the GCE electrode surface, the electrochemical activity of the GCE/MIL-53(Fe) electrode was stable, and the MIL$53(\mathrm{Fe})$ with a high electrochemically effective surface area was able to significantly enhance the electrochemical response of the WE. These data also further confirmed that in this study, the drop-casting method used to immobilize the MIL-53(Fe) on the WE surface was simple, convenient, and effective.

3.3. Detection of $\mathrm{Cd}(\mathrm{II})$ Ions Using MIL-53(Fe)-Based Electrochemical Sensors. To assess the ability of GCE/MIL$53(\mathrm{Fe})$ as an electrochemical sensor for detection of cadmium (Cd(II)) ions in aqueous solutions, the DPV of the GCE/bare and GCE/MIL-53(Fe) electrodes were recorded in $0.1 \mathrm{M} \mathrm{ABS}$ ( $\mathrm{pH}=5.0)$ solution containing $20 \mu \mathrm{M} \mathrm{Cd}(\mathrm{II})$ (Figure 5). As can be observed in Figure 5 (curve a), with GCE, no obvious response was observed when the accumulation process was carried out for $120 \mathrm{~s}$ at $-1.2 \mathrm{~V}$ in the solution containing $20 \mu \mathrm{M} \mathrm{Cd}^{2+}$ and $0.1 \mathrm{M} \mathrm{ABS}$ buffer $(\mathrm{pH}=5.0)$. This result implies that with the bare GCE, the ability to be used as an electrochemical sensor for detection of cadmium ions in aqueous solutions was almost negligible.

In contrast, the DPV result of GCE/MIL-53(Fe) (Figure 5, curve b) showed a strong response peak at $-0.75 \mathrm{~V}$ with the peak current $I_{\text {peak }}=37.29 \mu \mathrm{A}$, which characterizes the presence of $\mathrm{Cd}(\mathrm{II})$ ions in the aqueous solution, although the concentration of cadmium ions is relatively low 


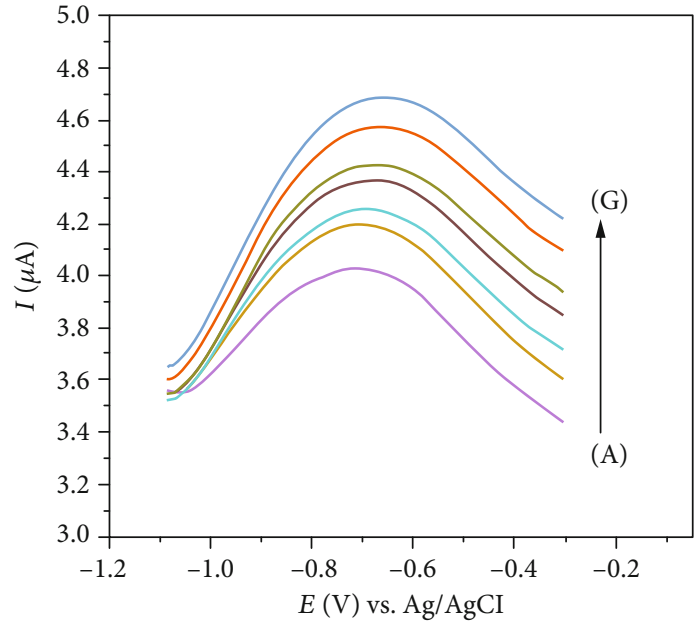

(a)

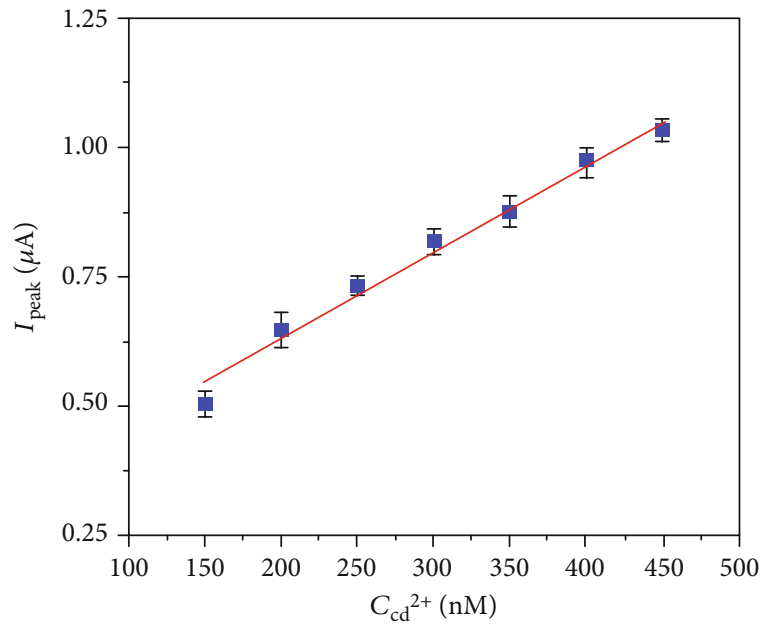

(b)

Figure 6: (a) DPV results of GCE/MIL-53(Fe) electrodes in Cd(II) solutions (with 0.1 M ABS (pH = 5.0)). Cd(II) concentrations (from A to G): 150, 200, 250, 300, 350, 400, and $450 \mathrm{nM}$; (b) response of the electrochemical sensors to different concentrations of Cd(II) ions.

TABLE 1: Comparison of the electrochemical sensor with someone else's in the previous literature.

\begin{tabular}{|c|c|c|c|}
\hline Surface modification & Linear range $(\mathrm{M})$ & Detection limit (M) & Reference \\
\hline GCE/chitosan-carbon nanotubes & $1.334 \times 10^{-5}-3.950 \times 10^{-5}$ & $7.1 \times 10^{-6}$ & [47] \\
\hline GCE/LAL*-AuNPs & $3.0 \times 10^{-7}-1.4 \times 10^{-6}$ & $3.0 \times 10^{-7}$ & [48] \\
\hline GCE/MIL-100(Cr) & $0-1.0 \times 10^{-5}$ & $4.4 \times 10^{-8}$ & [49] \\
\hline GCE/porous carbon-PdNPs & $5.0 \times 10^{-7}-5.5 \times 10^{-6}$ & $4.1 \times 10^{-8}$ & {$[50]$} \\
\hline GCE/MIL-53(Fe) & $1.5 \times 10^{-7}-4.5 \times 10^{-7}$ & $1.6 \times 10^{-8}$ & This work \\
\hline
\end{tabular}

${ }^{*}$ LAL: laser ablation in liquid.

$(20 \mu \mathrm{M})$. This result implies that the electrochemical sensor based on the MIL-53(Fe)-modified GCE can be used for determination of $\mathrm{Cd}$ (II) ions in aqueous solutions.

These obtained results can be attributed to the MIL$53(\mathrm{Fe})$ material with abundant adsorption sites and a large surface area, which can adsorb Cd(II) ions from the aqueous solution, leading the $\mathrm{Cd}(\mathrm{II})$ ion enrichment process onto the GCE/MIL-53(Fe) surface. Therefore, the electrochemical measurements were performed to detect the presence of $\mathrm{Cd}(\mathrm{II})$ ions on the electrode surface at low concentration. In addition, the enhanced current at the GCE/MIL-53(Fe) electrode compared to the bare GCE also indicates that the obtained MIL-53(Fe) with the high electrochemically effective surface area exhibits electrocatalytic activity to the reduction of the target. These above results suggest that using MIL$53(\mathrm{Fe})$ material in development of the electrochemical sensor for detection of $\mathrm{Cd}$ (II) ions is totally suitable.

Figure 6(a) shows the DPV response results of the GCE/MIL-53(Fe) with different $\mathrm{Cd}(\mathrm{II})$ concentrations. As can be seen, the increase in the concentration of Cd(II) target caused an increase in the peak current $\left(I_{\text {peak }}\right)$ of the responses. The change in the electrochemical signal was obtained even at low concentration of $\mathrm{Cd}(\mathrm{II})$ ions $(150 \mathrm{nM})$. And this phenomenon becomes more obvious when the target concentra- tion continues to rise (up to $450 \mathrm{nM}$ ). The above results are explained that when $\mathrm{Cd}(\mathrm{II})$ ions in the aqueous solutions increase, the amount of $\mathrm{Cd}(\mathrm{II})$ ions accumulated on the surface of the MIL-53(Fe) layer increases, which leads to increasing in response current of the DPV results. The sensitivity of the electrochemical sensors was investigated by plotting $I_{\text {peak }}$ versus different $\mathrm{Cd}^{2+}$ concentrations (Figure 6(b)). It shows that a linear relationship between $I_{\text {peak }}$ vs. $\left[\mathrm{Cd}^{2+}\right]$ in the range from $150 \mathrm{nM}$ to $450 \mathrm{nM}$ is $I_{\text {peak }}(\mu \mathrm{A})=0.2946$ $+0.0017 \times\left[\mathrm{Cd}^{2+}\right](\mathrm{nM})$ with a correlation coefficient of $R^{2}$ $=0.9809$. Based on a signal-to-noise ratio characteristic of $3(\mathrm{~S} / \mathrm{N}=3)[32,46]$, the detection limit of $\mathrm{Cd}^{2+}$ ions on GCE/MIL-53(Fe) was estimated to be $16 \mathrm{nM}$. The fabricated electrochemical sensor was compared to someone else's which has been reported in the previous studies (Table 1). Results in Table 1 indicate that the GCE/MIL-53(Fe) in this work has a great applied potential for $\mathrm{Cd}^{2+}$ determination on the terms including simple fabrication, direct detection, rapid analysis time, and high sensitivity.

\section{Conclusion}

We have synthesized the metal-organic framework MIL$53(\mathrm{Fe})$ using the effective hydrothermal method with 
optimized synthesis conditions. The synthesized MIL-53(Fe) was characterized by XRD, SEM/TEM, and FT-IR measurements, and the obtained results indicated that the formed MIL-53(Fe) was a single phase with narrow size distribution and the mean size was around $800 \mathrm{~nm}$. A layer of MIL53(Fe)-modified glassy carbon electrode (GCE/MIL-53(Fe)) was fabricated via the simple drop-casting technique. The $\mathrm{CV}$ and EIS measurements of the GCE/MIL-53(Fe) electrode indicated that the MIL-53(Fe) layer with the small particle size and the high electrochemically effective surface area was able to increase the electrochemical response and improve the sensitivity of the electrochemical sensor. The novel electrochemical sensor based on the MIL-53(Fe) was designed and developed to detect $\mathrm{Cd}(\mathrm{II})$ ions in aqueous solutions, and the detection limit of the sensor was $16 \mathrm{nM}$. The evaluated results demonstrated that the metal-organic framework MIL-53(Fe)-modified glassy carbon electrode (GCE/MIL-53(Fe)) has great promising for $\mathrm{Cd}^{2+}$ ion sensing in water samples with expressed advantages such as high sensitivity, direct detection, and rapid analysis time.

\section{Data Availability}

The data used to support the findings of this study are included within the article.

\section{Conflicts of Interest}

The authors declare that they have no conflicts of interest regarding the publication of this paper.

\section{Acknowledgments}

This research is supported by the Vietnam National Foundation for Science and Technology Development (NAFOSTED) under grant number 104.03-2019.19.

\section{References}

[1] J. Li, C. Yu, Y. N. Wu et al., "Novel sensing platform based on gold nanoparticle-aptamer and Fe-metal-organic framework for multiple antibiotic detection and signal amplification," Environment International, vol. 125, pp. 135-141, 2019.

[2] L. Ma, X. Zhang, M. Ikram, M. Ullah, H. Wu, and K. Shi, "Controllable synthesis of an intercalated ZIF-67/EG structure for the detection of ultratrace $\mathrm{Cd}^{2+}, \mathrm{Cu}^{2+}, \mathrm{Hg}^{2+}$ and $\mathrm{Pb}^{2+}$ ions," Chemical Engineering Journal, vol. 395, article 125216, 2020.

[3] X. Xu, X. Niu, X. Li, Z. Li, D. Du, and Y. Lin, "Nanomaterialbased sensors and biosensors for enhanced inorganic arsenic detection: a functional perspective," Sensors and Actuators B: Chemical, vol. 315, article 128100, 2020.

[4] H. A. Vu, M. H. Nguyen, H. A. Vu-Thi et al., "Speciation analysis of arsenic compounds by high-performance liquid chromatography in combination with inductively coupled plasma dynamic reaction cell quadrupole mass spectrometry: application for Vietnamese rice samples," Journal of Analytical Methods in Chemistry, vol. 2019, Article ID 5924942, 10 pages, 2019.

[5] H. Chen, T. Yang, F. Liu, and W. Li, "Electrodeposition of gold nanoparticles on cu-based metal-organic framework for the electrochemical detection of nitrite," Sensors and Actuators B: Chemical, vol. 286, pp. 401-407, 2019.

[6] C.-S. Liu, J. Li, and H. Pang, "Metal-organic framework-based materials as an emerging platform for advanced electrochemical sensing," Coordination Chemistry Reviews, vol. 410, article 213222, 2020.

[7] T. R. Das and P. K. Sharma, "Sensitive and selective electrochemical detection of $\mathrm{Cd}^{2+}$ by using bimetal oxide decorated graphene oxide $\left(\mathrm{Bi}_{2} \mathrm{O}_{3} / \mathrm{Fe}_{2} \mathrm{O}_{3} @ \mathrm{GO}\right)$ electrode," Microchemical Journal, vol. 147, article 1203, 2019.

[8] S. Duan and Y. Huang, "Electrochemical sensor using $\mathrm{NH}_{2}$ MIL-88(Fe)-rGO composite for trace $\mathrm{Cd}^{2+}, \mathrm{Pb}^{2+}$, and $\mathrm{Cu}^{2+}$ detection," Journal of Electroanalytical Chemistry, vol. 807, pp. 253-260, 2017.

[9] X. Fang, B. Zong, and S. Mao, "Metal-organic frameworkbased sensors for environmental contaminant sensing," Nano-Micro Letters, vol. 10, no. 4, p. 64, 2018.

[10] D. Feng, P. Li, X. Tan et al., "Electrochemiluminescence aptasensor for multiple determination of $\mathrm{Hg}^{2+}$ and $\mathrm{Pb}^{2+}$ ions by using the MIL-53(Al)@CdTe-PEI modified electrode," Analytica Chimica Acta, vol. 1100, pp. 232-239, 2020.

[11] X. Liao, H. Fu, T. Yan, and J. Lei, "Electroactive metal-organic framework composites: design and biosensing application," Biosensors and Bioelectronics, vol. 146, article 111743, 2019.

[12] L. T. Tran, H. V. Tran, H. Thi Minh Dang, C. D. Huynh, and T. A. Mai, "Silver nanoparticles decorated polyaniline nanowires-based electrochemical DNA sensor: two-step electrochemical synthesis," Journal of the Electrochemical Society, vol. 167 , no. 8 , article $087508,2020$.

[13] H. V. Le and Q. T. Le, "Electrochemical preparation of polyaniline- supported $\mathrm{Cu}-\mathrm{CuO}$ core-shell on 316L stainless steel electrodes for nonenzymatic glucose sensor," Advances in Polymer Technology, vol. 2020, Article ID 6056919, 7 pages, 2020.

[14] A. Mourya, B. Mazumdar, and S. K. Sinha, "Determination and quantification of heavy metal ion by electrochemical method," Journal of Environmental Chemical Engineering, vol. 7, no. 6, article 103459, 2019.

[15] T. L. Tran, T. X. Chu, D. C. Huynh, D. T. Pham, T. H. T. Luu, and A. T. Mai, "Effective immobilization of DNA for development of polypyrrole nanowires based biosensor," Applied Surface Science, vol. 314, pp. 260-265, 2014.

[16] H. V. Tran, N. D. Nguyen, B. Piro, and L. T. Tran, "Fabrication of a quinone containing layer on gold nanoparticles directed to a label-free and reagentless electrochemical miRNA sensor," Analytical Methods, vol. 9, no. 18, pp. 2696-2702, 2017.

[17] V. Mariyappan, S. Manavalan, S.-M. Chen, G. Jaysiva, P. Veerakumar, and M. Keerthi, "Sr@FeNi-S nanoparticle/carbon nanotube nanocomposite with superior electrocatalytic activity for electrochemical detection of toxic mercury(II)," ACS Applied Electronic Materials, vol. 2, no. 7, pp. 19431952, 2020.

[18] P. Veerakumar, S. M. Chen, R. Madhu, V. Veeramani, C. T. Hung, and S. B. Liu, "Nickel nanoparticle-decorated porous carbons for highly active catalytic reduction of organic dyes and sensitive detection of hg(II) ions," ACS Applied Materials \& Interfaces, vol. 7, no. 44, pp. 24810-24821, 2015.

[19] T. L. Tran, T. T. Nguyen, T. T. Huyen Tran, V. T. Chu, Q. Thinh Tran, and A. Tuan Mai, "Detection of influenza A virus using carbon nanotubes field effect transistor based DNA sensor," Physica E: Low-dimensional Systems and Nanostructures, vol. 93, pp. 83-86, 2017. 
[20] Y. Xue, S. Zheng, H. Xue, and H. Pang, "Metal-organic framework composites and their electrochemical applications," Journal of Materials Chemistry A, vol. 7, no. 13, pp. 7301-7327, 2019.

[21] R. Hu, X. Zhang, K.-N. Chi, T. Yang, and Y.-H. Yang, "Bifunctional MOFs-based ratiometric electrochemical sensor for multiplex heavy metal ions," ACS Applied Materials \& Interfaces, vol. 12, no. 27, article 30770, p. 30778, 2020.

[22] Y. Wang, L. Wang, W. Huang et al., "A metal-organic framework and conducting polymer based electrochemical sensor for high performance cadmium ion detection," Journal of Materials Chemistry A, vol. 5, no. 18, pp. 8385-8393, 2017.

[23] L. Jiao, J. Y. R. Seow, W. S. Skinner, Z. U. Wang, and H.L. Jiang, "Metal-organic frameworks: structures and functional applications," Materials Today, vol. 27, pp. 43-68, 2019.

[24] X. Wang, Y. Qi, Y. Shen et al., “A ratiometric electrochemical sensor for simultaneous detection of multiple heavy metal ions based on ferrocene-functionalized metal-organic framework," Sensors and Actuators B: Chemical, vol. 310, article 127756, 2020.

[25] S. Guo, Y. Zhu, Y. Yan et al., "(Metal-organic framework)polyaniline sandwich structure composites as novel hybrid electrode materials for high-performance supercapacitor," Journal of Power Sources, vol. 316, pp. 176-182, 2016.

[26] T. A. Vu, G. H. Le, C. D. Dao et al., "Arsenic removal from aqueous solutions by adsorption using novel MiL-53(Fe) as a highly efficient adsorbent," RSC Advances, vol. 5, no. 7, pp. 5261-5268, 2015.

[27] S. Gu, Z. Bai, S. Majumder, B. Huang, and G. Chen, "Conductive metal-organic framework with redox metal center as cathode for high rate performance lithium ion battery," Journal of Power Sources, vol. 429, pp. 22-29, 2019.

[28] A. Gupta, S. K. Bhardwaj, A. L. Sharma, K. H. Kim, and A. Deep, "Development of an advanced electrochemical biosensing platform for E. coli using hybrid metal-organic framework/polyaniline composite," Environmental Research, vol. 171, pp. 395-402, 2019.

[29] W. Ye, Y. Li, J. Wang et al., "Electrochemical detection of trace heavy metal ions using a Ln-MOF modified glass carbon electrode," Journal of Solid State Chemistry, vol. 281, article 121032, 2020.

[30] J. Zhou, G. Tian, L. Zeng, X. Song, and X. W. Bian, "Nanoscaled metal-organic frameworks for biosensing, imaging, and cancer therapy," Advanced Healthcare Materials, vol. 7, no. 10, article 1800022, 2018.

[31] D. T. C. Nguyen, H. T. N. Le, T. S. Do et al., "Metal-organic framework MIL-53(Fe) as an adsorbent for ibuprofen drug removal from aqueous solutions: response surface modeling and optimization," Journal of Chemistry, vol. 2019, Article ID 5602957, 11 pages, 2019.

[32] H. V. Tran, C. D. Huynh, T. D. Le, and H. S. Hoang, "Hydroxyapatite nano-rods/chitosan modified glassy carbon electrode for $\mathrm{Cu}(\mathrm{II})$ ions determination," Electronic Materials Letters, vol. 16, no. 4, pp. 396-403, 2020.

[33] H. V. Tran, L. D. Tran, C. T. Ba et al., "Synthesis, characterization, antibacterial and antiproliferative activities of monodisperse chitosan-based silver nanoparticles," Colloids and Surfaces A: Physicochemical and Engineering Aspects, vol. 360, no. 1-3, pp. 32-40, 2010.

[34] J. Gordon, H. Kazemian, and S. Rohani, "Rapid and efficient crystallization of MIL-53(Fe) by ultrasound and microwave irradiation," Microporous and Mesoporous Materials, vol. 162, pp. 36-43, 2012.

[35] C. Scherb, A. Schödel, and T. Bein, "Directing the structure of metal-organic frameworks by oriented surface growth on an organic monolayer," Angewandte Chemie International Edition, vol. 47, no. 31, pp. 5777-5779, 2008.

[36] J. Gordon, H. Kazemian, and S. Rohani, "MIL-53(Fe), MIL101, and SBA-15 porous materials: potential platforms for drug delivery," Materials Science and Engineering: C, vol. 47, pp. 172-179, 2015.

[37] P. Horcajada, C. Serre, G. Maurin et al., "Flexible porous metal-organic frameworks for a controlled drug delivery," Journal of the American Chemical Society, vol. 130, no. 21, pp. 6774-6780, 2008.

[38] A. Banerjee, R. Gokhale, S. Bhatnagar et al., "MOF derived porous carbon- $\mathrm{Fe}_{3} \mathrm{O}_{4}$ nanocomposite as a high performance, recyclable environmental superadsorbent," Journal of Materials Chemistry, vol. 22, no. 37, article 19694, 2012.

[39] C. Gong, D. Chen, X. Jiao, and Q. Wang, "Continuous hollow $\alpha-\mathrm{Fe}_{2} \mathrm{O}_{3}$ and $\alpha$-Fe fibers prepared by the sol-gel method," Journal of Materials Chemistry, vol. 12, no. 6, pp. 1844-1847, 2002.

[40] T.-X. Chu, V.-P. Vu, H.-T. Tran, T.-L. Tran, Q.-T. Tran, and T. Le Manh, "Molecularly imprinted polyaniline nanowirebased electrochemical biosensor for chloramphenicol detection: a kinetic study of aniline electropolymerization," Journal of the Electrochemical Society, vol. 167, no. 2, article 027527, 2020.

[41] S. Corona-Avendaño, G. Alarcón-Angeles, M. T. RamírezSilva, G. Rosquete-Pina, M. Romero-Romo, and M. PalomarPardavé, "On the electrochemistry of dopamine in aqueous solution. Part I: the role of [SDS] on the voltammetric behavior of dopamine on a carbon paste electrode," Journal of Electroanalytical Chemistry, vol. 609, no. 1, pp. 17-26, 2007.

[42] J. Li, L. He, J. Jiang et al., "Facile syntheses of bimetallic Prussian blue analogues $\left(\mathrm{K}_{\mathrm{x}} \mathrm{M}\left[\mathrm{Fe}(\mathrm{CN})_{6}\right] \cdot \mathrm{nH}_{2} \mathrm{O}, \mathrm{M}=\mathrm{Ni}, \mathrm{Co}\right.$, and $\mathrm{Mn})$ for electrochemical determination of toxic 2-nitrophenol," Electrochimica Acta, vol. 353, article 136579, 2020.

[43] S. J. Konopka and B. McDuffie, "Diffusion coefficients of ferriand ferrocyanide ions in aqueous media, using twin-electrode thin-layer electrochemistry," Analytical Chemistry, vol. 42, no. 14, pp. 1741-1746, 2002.

[44] Y. Ge, M. B. Camarada, L. Xu et al., "A highly stable black phosphorene nanocomposite for voltammetric detection of clenbuterol," Mikrochimica Acta, vol. 185, no. 12, article 566, 2018.

[45] J. Krejci, Z. Sajdlova, V. Nedela et al., "Effective surface area of electrochemical sensors," Journal of the Electrochemical Society, vol. 161, no. 6, pp. B147-B150, 2014.

[46] H. V. Tran, B. Piro, S. Reisberg, L. D. Tran, H. T. Duc, and M. C. Pham, "Label-free and reagentless electrochemical detection of microRNAs using a conducting polymer nanostructured by carbon nanotubes: application to prostate cancer biomarker miR-141," Biosensors and Bioelectronics, vol. 49, pp. 164-169, 2013.

[47] K.-H. Wu, H.-M. Lo, J.-C. Wang, S.-Y. Yu, and B.-D. Yan, "Electrochemical detection of heavy metal pollutant using crosslinked chitosan/carbon nanotubes thin film electrodes," Materials Express, vol. 7, no. 1, pp. 15-24, 2017.

[48] X. Xu, G. Duan, Y. Li et al., "Fabrication of gold nanoparticles by laser ablation in liquid and their application for simultaneous electrochemical detection of $\mathrm{Cd}^{2+}, \mathrm{Pb}^{2+}, \mathrm{Cu}^{2+}, \mathrm{Hg}^{2+}$," 
ACS Applied Materials \& Interfaces, vol. 6, no. 1, pp. 65-71, 2013.

[49] D. Wang, Y. Ke, D. Guo, H. Guo, J. Chen, and W. Weng, "Facile fabrication of cauliflower-like MIL-100(Cr) and its simultaneous determination of $\mathrm{Cd}^{2+}, \mathrm{Pb}^{2+}, \mathrm{Cu}^{2+}$ and $\mathrm{Hg}^{2+}$ from aqueous solution," Sensors and Actuators B: Chemical, vol. 216, pp. 504-510, 2015.

[50] P. Veerakumar, V. Veeramani, S. M. Chen, R. Madhu, and S. B. Liu, "Palladium nanoparticle incorporated porous activated carbon: electrochemical detection of toxic metal ions," ACS Applied Materials \& Interfaces, vol. 8, no. 2, pp. 13191326, 2016. 